\title{
The practice of reporting adverse events in a teaching hospital
}

\author{
A prática de notificação de eventos adversos em um hospital de ensino \\ La práctica de notificación de eventos adversos en un hospital de enseñanza
}

Andréia Guerra Siman ${ }^{1}$, Simone Graziele Silva Cunha ${ }^{2}$, Maria José Menezes Brito $^{3}$

How to cite this article:

Siman AG, Cunha SGS, Brito MJM. The practice of reporting adverse events in a teaching hospital. Rev Esc Enferm USP. 2017;51:e03243. DOI: http://dx.doi. org/10.1590/S1980-220X2016045503243

\author{
${ }^{1}$ Universidade Federal de Viçosa, \\ Viçosa, MG, Brazil. \\ ${ }^{2}$ Universidade do Estado de Minas \\ Gerais, Belo Horizonte, MG, Brazil. \\ ${ }^{3}$ Universidade Federal de Minas Gerais, \\ Belo Horizonte, MG, Brazil.
}

\begin{abstract}
Objective: Understanding the practice of reporting adverse events by health professionals. Method: A qualitative case study carried out in a teaching hospital with participants of the Patient Safety Center and the nursing team. The collection took place from May to December 2015, and was conducted through interviews, observation and documentary research to treat the data using Content Analysis. Results: 31 professionals participated in the study. Three categories were elaborated: The practice of reporting adverse events; Barriers in the effective practice of notifications; The importance of reporting adverse events. Conclusion: Notification was permeated by gaps in knowledge, fear of punishment and informal communication, generating underreporting. It is necessary to improve the interaction between leaders and professionals, with an emphasis on communication and educational practice.
\end{abstract}

DESCRIPTORS

Patient Safety; Nursing Team; Security Management; Quality of Health Care; Medical errors. 


\section{INTRODUCTION}

The occurrence of adverse events (AE) is recognized as a failure in patient safety, and may occur between $5 \%$ and $17 \%$, and for which $60 \%$ may be preventable. Thus, patient safety should be seen as a set of strategies/interventions capable of preventing and reducing the risk of harm to the patient due to health care ${ }^{(1)}$.

Among the consequences of the injuries or injuries caused to the patient as a result of care, the most significant are costs of hospital admissions, hospital stay, the need for diagnostic and therapeutic intervention, and social costs such as increased medication, absence from work and premature death ${ }^{(2)}$.

Several failures are needed for an $\mathrm{AE}$ to occur such as structural and inadequate practices, carelessness or inadequate behavior of professionals, triggered by multiple factors ${ }^{(2)}$. AEs can be analyzed through the Swiss cheese model which consists of a barrier model, also called cascade logic; it adapts to high technology systems by its defensive layers, such as alarms, individuals in finalist actions or administrative controls to protect potential victims and situations of risk. The barriers are like slices of Swiss cheese with many holes $^{(2-3)}$. When the holes are momentarily aligned, the trajectory of the accident is allowed to occur.

Actions to promote patient safety and improve quality in health services have been a growing interest in research and have been increasingly disseminated in health organizations with worldwide priority in an attempt to reduce the occurrence of the number of preventable incidents. When an incident occurs, it is useful to determine whether it consisted of an $\mathrm{AE}$, meaning if it harmed the patient. In recent years, research on the incidence, nature and impacts of $\mathrm{AE}$ have contributed to the knowledge of the problem's magnitude. In Brazil, Portugal and Spain, studies have shown an incidence of $7.6 \%, 11.1 \%$ and $8.4 \%$ of patients with $\mathrm{AE}$ respectively, and $42 \%$ to $66 \%$ of those were considered avoidable ${ }^{(4-5)}$.

In order to identify and recover from incidents, it is significant to know its types and consequences for the patient. Incidents (related to health care) can be classified as: risky circumstance; near-miss, incident without damage, or incident with damage (which can also be referred to as an adverse event $)^{(1)}$, and which are undesired complications arising from the care provided ${ }^{(1,3)}$.

Considering the relevance of $\mathrm{AE}$, the World Alliance for Patient Safety was established in 2004 with international strategies, guidelines and goals ${ }^{(1)}$. In Brazil in 2013, the National Patient Safety Program was created to monitor risks, qualify care and encourage the development of a safety culture in health institutions ${ }^{(6)}$.

An AE must be notified to the National Health Surveillance Agency (Agência Nacional de Vigilância Sanitária - $A N V I S A)$ in the notification system (NOTIVISA), which is a computerized system where professionals, institutions and individuals can report problems related to the use of technologies, healthcare processes, health products, incidents and $\mathrm{AEs}^{(7)}$.

In this way, some initiatives have already been carried out to reduce health incidents. However, in developing countries there is still the need to conduct research that can reveal aspects about these events ${ }^{(1)}$, because the risk of death in hospitals by mistake during hospitalization or the risk of an $\mathrm{AE}$ is still high ${ }^{(2,4)}$. In addition, care that lacks in quality and safety in services may lead to the patient being admitted to intensive care (ICU), to cardiac arrest, or even sudden death ${ }^{(8)}$.

In this sense, the present research intends to contribute to adopting safe practices with an emphasis on the notification and prevention of AEs. However, in order to develop a patient safety culture in health institutions, the management and the professionals involved in the care need to make a commitment, and a strong spirit of cohesion between the different departments is also needed as essential factors for guaranteeing safe care, both for the professional and for the patient ${ }^{(9)}$.

Considering the presented ideas, we ask: how does the practice of reporting adverse events in the daily life of professionals occur? It is assumed that the notification of incidents is underreported in the reality of the institution, which may be related to the adopted notification system where the professional notifying the incident needs to identify him/herself(10).

This research aims to understand the practice of reporting adverse events by health professionals.

\section{METHOD}

This is a qualitative research implementing the Case Study research strategy framework aiming to analyze a social unit, seeking to answer the "how" and the "why" phenomena occur, and is ideal for organizational studies seeking to portray reality in a complete and profound way ${ }^{(11)}$.

A hospital that develops quality improvement strategies and has a risk management committee was chosen for defining the study scenario. It is a teaching hospital that is part of the Sentinela Hospitals Network (Rede de Hospitais Sentinela), located in the East Zone of the Forest of Minas Gerais. It has 116 beds, six adult hospitalization units and an average of 5,232 patient-days per month. It is a reference service of a health region composed of nine municipalities.

The participants of the research were professionals working at the Patient Safety Center (NSP - Núcleo de Segurança do Paciente) and the Nursing Team (nurses and nursing technicians). The inclusion criteria were: to be a member of the NSP, and for the nursing team to work at hospitalization units, medical and surgical clinics, and to have been working for at least 1 year. The choice of interviewing the hospitalization unit teams was based on the results of a study in which the objective was to evaluate the incidence of adverse events in hospitals in Brazil. Their results showed that the nursing ward was the most frequent site of adverse events $(56.9 \%)^{(4)}$. NSP professionals were chosen because they are the ones who manage and prescribe actions to achieve patient safety. All the nurses on the nursing team were interviewed, and data saturation criteria ${ }^{(11)}$ was used for the nursing technical team where interviews were interrupted when the collected data became repetitive and redundant. 
Among the core members, two professionals were on medical leave and one refused to participate, totaling 12 participants. There were seven nurses and saturation occurred in the $12^{\text {th }}$ interview with the technicians, thus making 31 participants.

Data collection was performed through triangulation with primary and secondary data. The primary data were collected through interviews with a semi-structured script and observation was recorded in a field journal. Before starting the interviews, a pilot test was conducted to evaluate the quality of the interview script, with no need for changes. The observation occurred at the hospitalization unit to better understand the notification practice during the professionals' work process. It lasted 72 hours, with an average of 12 hours in each hospitalization unit. Secondary data were obtained through documental research (documents related to quality management, reports, protocols, indicators, records and the NSP action plan). Data were collected from May to December 2015.

The interviews were recorded and transcribed in full and lasted from 10 to 100 minutes, being coded with Portuguese acronyms: NSP (Núcleo de Segurança do Paciente - Patient Safety Center), N (Nurse), or NT (nursing technician), followed by the interview number. The questions sought to understand knowledge aspects in the area of patient safety and $\mathrm{AE}$, practices and notifications to achieve safety, difficulties and facilities to achieve international goals and the importance of reporting incidents and AE.

Categorical and Thematic Content Analysis was used for data analysis ${ }^{(12)}$, which consists of a set of communication analysis techniques performed around three chronological steps: pre-analysis, material exploration and treating the results. First, all the material was organized in the pre-analysis and a "fluctuating" reading was performed, then exhaustive readings allowing for constituting the corpus, as formulated impressions based on the data content emerged. Next, the codification and categorization process of the raised topics were carried out with a systematic procedure allowing to highlight the "registered units" (words/topics) constituting three categories. After categorization, the content was analyzed with interpretation and data inferences based on the literature. According to systematic procedures, the constructed categories were: The practice of reporting adverse events; Barriers to effective practice of reporting adverse events; and The importance of reporting adverse events.

All participants signed the Free and Informed Consent Form in compliance with Resolution 466/12 of the Ministry of Health, and the research was approved by the Research Ethics Committee of the Hospital and by the Research Ethics Committee of UFMG (Universidade Federal de Minas Gerais), under the Opinion No. 1.072.502.

\section{RESULTS}

31 professionals participated in this research: 12 NSP (six nurses, one nursing technician, one nutritionist, one pharmacist, two administrators and one domestic economist), 7 nurses and 12 nursing technicians; in total, 26 women (84\%) and 5 men (16\%), aged between 24 and 51 years old.
The average time after graduation was 9 years, and 8 years working at the institution. In relation to other professional relationships, 49\% ( $\mathrm{n}=15)$ worked somewhere else and 51\% $(n=16)$ worked only at the analyzed institution. Only four participants had prior knowledge about patient safety, and 27 had obtained it from the institution.

\section{THE PRACTICE OF REPORTING ADVERSE EVENTS}

This category describes the scenario and practice of $\mathrm{AE}$ notification in the studied institution. Among some aspects it is important to note that the notification is voluntary, manual, done on printed forms, and after registration it is sent to the NSP/Risk Management. In 2012, the form was restricted to notifications of technical complaints. In 2013, there was an increase in the number of AE notification fields (venous access complications, medication error, falling from the bed, pressure ulcers, hospital infection, loss of probes, etc.) with an option space for the professional to identify him/herself. There are descriptive SOPs (Standard Operating Procedures) on how to notify an AE.

Despite the provision of the mentioned forms by the institution, there were reports of professionals being unaware of the notification form:

Not that I know about. If there is any sheet there for the notification, I don't know (NT21).

Oh, it has never happened to me. The falling, it has never happened to me, or any other events. There is one for venipuncture in the room, printed. Now for falling from the bed, it has never really happened to me. I've never seen a printed form here, no (N20).

In our file of the patient's evolution I write falling from one's height itself, falling from the bed. As far as I know there is no other (form), no (NT18).

It was possible to observe difficulties in communication, since the professionals receive little information on how to carry out the notification practice, which reduces the amount of registrations. Failure to complete the notification form was pointed out by the professionals:

No, I've never notified. I think that all that I said (about the main risks I identify at the institution) is the most important thing (NT27).

I think they notify verbally. Let's assume something happened in the ward, they (NT) come to the pharmacy, talk to us, but they don't notify. I ask them to notify but not everybody does so (NSP11).

Some nurses, nursing technicians and even NSP members have little knowledge about how to notify if an AE occurs:

Even for me, I still have difficulties. I have not made any notifications yet. I haven't and I think I'm going to be a bit lost even though I've already been through everything (NSP5).

But I think they (technicians) still have no clue on how to notify (NSP9).

No one ever taught me! I don't know what to do. If, for example, someone falls out of bed, I know that at the end of the month they add up all the indicators, but I don't agree with everything (N3). 
Another relevant aspect in the N3 statement is that there is a disagreement about data processing, meaning that the indicators do not reveal the reality of the institution, in the professionals' point of view:

I've been approached about a medication error. For example, a dosing error, it was supposed to be $2.5 \mathrm{mg}$ and the medication was $5 \mathrm{mg}$, and all of it was given. In fact, it only wasn't so bad because it was a low dosage, but it happens. She didn't notify, she approached me, "what should I do?" (NSP11).

The professionals do not feel prepared to notify as they lack professional training, and the observation revealed that the biggest notifications are of technical complaints.

I think they can more easily identify pharmacovigilance issues than internal events. They bave more freedom to notify about a technical complaint (NSP2).

\section{Barriers to Effective Adverse Event Reporting}

In notifications of AEs, barriers related to a lack of knowledge by professionals on basic notions such as what is an error, $\mathrm{AE}$ and the concept of patient safety in itself were evidenced:

I don't know what an adverse event is. No, because here we inform the nurse and the nurse does it, right? (NT28).

You have job security which is related to us. Not to hurt, or to take risks. There is isolation, precaution of contact, precaution of aerosols, do you get it? It's identified with signs and all! There are procedures for us to enter there (in the room), with the right PPEs (NT17).

Many people changed the concept and others already have a basic idea of what it is. So at the meetings for now they are clarifying this issue of notification and the types of notification. What is the purpose of each, to whom to appeal, what should be notified and an alert so that everyone in the center can be aware of what is happening (NSP10).

The professionals also reported that the practice of notifying an $\mathrm{AE}$ is hampered by a lack of preparation, knowledge and forgetfulness:

I still don't feel prepared to notify. I know you have to notify, that you have to start this habit, but I forget. Something happens which I know it should be notified, but at the time I don't mean any harm (by not doing it)! I think myself and many other parts still need to improve at this. It's not that I don't want to notify, but I forget. I really have to add this into my day to day work because I have no notifications (NSP10).

I notify everything, but I think most nurses still don't notify. They know how to do so because they were trained, it was taught to technical staff at the beginning that it's not only the nurse who notifies, but they don't like to notify. I have never seen a technician notifying (N25).

It was possible to identify a few notifications; some professionals recognize and justify the action:

The problem is that you have to stop what you're doing to notify and this is time you don't have, because we have to improvise a lot at work: an extension that does not work on time, you have to solve it because you're with the patient. And then you've had other problems, such as a cardiac arrest in the room, which is much more serious (NSP12).

Another identified aspect that hinders the AE notification process is the different ways professionals act in the same routine situations in face of the $\mathrm{AE}$, even though there is a step by step notification in standard operating procedures. Different ways of communicating AE by nursing technicians have been identified: communication to doctors or nurses, notes in medical records or records of occurrence, or they do not know what to do. None confirmed using the notification form. A punitive culture still prevails, which makes reporting difficult, affecting and reinforcing underreporting:

They expect me to notify something because at the hospital, unfortunately, the mentality is punitive. It's all punishment! In discourse it's not, but only in discourse (NSP9).

I think sometimes it can stick to the group, to the people who notify; even among the nurses, because we still work with a lot of underreporting. It's something the Center is always asking for. I think we could disclose more on a notice board what else is happening (NSP8).

The employee needs to be better prepared to report the event. But it's not like this: if I speak I will be warned! Same as a technician there at the ward. If a patient falls it's not his/her fault. But he doesn't notify because he thinks he'll be the one to blame and that he'll be punished. There's a lot of work to be done about this (NSP7).

\section{THE IMPORTANCE OF NOTIFYING ADVERSE EVENTS}

Despite the actual portrayed scenario and the difficulties encountered in the $\mathrm{AE}$ notification process, the interviewees perceive the importance of reporting, referring to notification as a source of useful information for improving patient care, obtaining records and subsidizing continuing education:

Notification is of great importance because it should be the basis for working on continuous learning; for working on ways of improving the care given. But the reality is this: notification is used as punishment $(\mathrm{N} 1)$.

Notifying? Oh let's suppose, if sometimes (he/she) fails to give some medication, or gives the wrong one, if you do anything that can harm the patient. Because then you do everything right, right? It protects us and the patient in some cases as well (NT29).

Falling from the bed or falling from one's own height, in the bathroom... we communicate to take tests. It's important because if it goes wrong it's our responsibility. I think it's important to do the notification, but there's a doctor here who told us that we're exaggerating (NT23).

Some interviewees stated that notification helps at detecting the causes, at the evaluation of the AEs and at the reduction of occurrences:

If there isn't a notification, you can't tell whether security-related issues are effective. I think we should do more (N3).

I think notification is needed, mainly to identify the causes, and what could be done to avoid it. So the more I notify, I have a 
statistic, I will work on it so that it doesn't occur any more, in order to decrease the indexes (N14).

This month there were ten reports of bed falls. Let's see what's happening to keep people from continuing to fall. I think it helps in avoiding future events (NSP6).

\section{DISCUSSION}

The topic of patient safety is related to $\mathrm{AE}$, since the occurrence of incidents directly interferes with the quality of life of those receiving health care.

The basis for a patient safety program is the voluntary reporting systems, a strategy to ensure quality recently structured in Latin American countries. These notification systems help to identify improvements in the development of safety culture ${ }^{(13)}$. However, different means can be used for the reports such as printed forms, telephone, fax, intranet or internet. The most used medium in Brazilian hospitals is still manual with printed forms ${ }^{(14)}$. Nevertheless, countries with greater experience such as Australia, Canada, the United States and the United Kingdom have advanced systems for reporting incidents ${ }^{(13)}$.

Findings in the observation of the notification form and analysis of the testimonies about implementation of the notification process in the studied institution reveal noncompliance to some aspects such as instructing the professional to fill out the form and anonymity in the notification. Emphasis is placed on the importance of the forms being clear, simple, fast-tracked, and that professionals are advised to complete them with the assurance of confidentiality of the notified information. In addition, the professional must do it anonymously, which increases the confidence of the professionals in reporting ${ }^{(10)}$.

It is also worth noting that despite studies pointing out that the notification can be manual or computerized, one study showed that electronic notification is more advantageous, increasing the quality of the reports between $58.7 \%$ and $62 \%$, leading to a reduction in deleted entries, and greater participation of professionals, mainly nursing technicians ${ }^{(14)}$. At the research scenario hospital, there is a lack of resources to install computers in all sectors, which from the view of the participants prevents advances in notifications.

The results presented evidence the way professionals act, diverging from the prescriptive context. They are better prepared to report technical complaints (which have not affected the patient yet) than an AE in their daily work. Even with an SOP to guide practice, practitioners claim they do not know how to notify. In this same perspective, a study published in 2013 showed that only implementing norms and guidelines were not enough to achieve significant improvements; adjustments on the information provided to the team were also needed ${ }^{(15)}$.

Regarding notification of technical complaints, the findings are consistent with a study carried out in a hospital unit that pointed out that the most reported events were the technical complaints related to pharmacovigilance ${ }^{(7)}$. The occurrence of other incidents which also compromise patient safety is still a challenge due to underreporting. It is worth clarifying that a technical complaint is any change or irregularity of a product or company related to technical or legal aspects that may lead to health problems ${ }^{(7)}$.

About the notification practice at the studied institution, the analysis made it possible to identify that $58 \%$ of the participants in the survey were unaware of the notification form and $67.7 \%$ never completed a notification. Similar results were found in a national survey, in which $76.8 \%$ of subjects never completed a notification ${ }^{(16)}$. Thus, the qualification process of health professionals for notification is $\operatorname{gradual}^{(7)}$, and under continuous construction until it is part of the daily routine, a lived reality.

Initiatives in relation to $\mathrm{AE}$ occurrence varied widely among participants, with the adoption of individual, isolated and personal conducts in disagreement with the prescriptive norms of the institution, such as those described in the $\mathrm{AE}$ SOP. A previous study identified the practice of informal communication and the omission of adverse events among professionals in hospital practice ${ }^{(17)}$. The perception and conduct of professionals in relation to errors may vary according to the institutional culture (punitive or not) ${ }^{(18)}$, and is also closely related to individual responsibility ${ }^{(19-20)}$.

Thus, it is important to invest in disseminating safety culture with an emphasis on education and communication, adopting conducts based on protocols, guidelines and SOPs, expanding safety knowledge according to the perspective of continuous construction, taking into account the reality of the institution and also the meanings and values that the professionals attribute to patient safety. A recent study in English health services highlights the importance of education, training and personal development of nursing and other professionals as important actors in the culture of patient safety to improve the quality of practices at these institutions ${ }^{(21)}$.

The term safety culture has received increasing attention and international priority, and can be understood as the sum of values, experiences, customs and practices that define the behavior of a group. Achieving this culture requires an understanding of values, beliefs, and norms about what is important in an organization and which actions and behavior related to patient safety are expected. The establishment of a safety culture is the key element of high reliability institutions ${ }^{(22)}$.

In this sense, in order to overcome knowledge gaps and increase the commitment to identify and reduce mistakes in professional practice, and in order to overcome the different ways of communicating or omitting an $\mathrm{AE}$, it is necessary that institutional management along with the support of professionals take positions that reinforce this culture, and which can be accomplished through communicative leadership, a non-punitive posture and personal development. These are skills and competencies developed by managers to improve reporting, however, they were not observed in the present study.

Another aspect observed in this study was a lack of strategies to involve patients in the analysis and prevention of incidents. Scholars have already proven the importance of patients reporting incidents and their relationship with patient safety, helping to develop a safety culture ${ }^{(23)}$. 
The results show that there is a gap in knowledge, with a fragmented view on patient safety and AE. The lack of knowledge or lack of understanding of the team that any professional is able to commit mistakes can lead to feelings of shame, guilt and fear, which can be aggravated by the punitive culture predominant at the institution under study, contributing to hiding the episodes ${ }^{(18,20)}$.

This is why a permanent education program and the encouragement of adherence to protocol and guidelines are vital aspects that should be part of the priorities list of NSP members, hospital managers and health professionals involved in care ${ }^{(24)}$. Nevertheless, professionals' fear of punishment found in the results may encourage underreporting ${ }^{(18)}$. The fact that it is a hospital that participates in the Sentinel Hospitals Network reinforces the need to stimulate the notifications. However, in practice it is observed that the environment is permeated by fear of punishment. Underreporting can occur due to several factors such as fear, guilt and the type of notification system, being one of the main difficulties of the voluntary notification $\operatorname{method}^{(13)}$.

Other studies have also revealed the existence of fear in reporting facing the investigative and analytical process, because taking responsibility was followed by orientation or warning ${ }^{(25)}$. Thus, the existence of the punitive culture at the studied institution undermines notification and learning with error, considering that punishment is different from accountability. It is necessary for the managers of the institution to understand that $\mathrm{AEs}$ are often directly related to failures in the system and work processes, not to the individual due to professional negligence or incompetence. Instead of looking for culprits, weaknesses in the process should be identified along with adoption of preventive measures, thus improving notifications, and consequently learning from the mistakes ${ }^{(18,20,24)}$.

It is worth emphasizing that risk is a constant reality in health organizations. Health outcomes are uncertain, often expressed in errors and complications. These results are determined by several factors related to developed activity, environmental conditions, individual and organizational factors such as ability and non-adherence to standards, as well as other random factors that cannot be explained. Thus, in order for the obtained result to be close to the expected result, correct clinical risk management is required which will help in obtaining better results ${ }^{(2,24)}$.

One of the problems identified at the research scenario institution that prevents the organization from achieving more positive results refers to skills at micro and macro levels and the involvement of all hierarchical levels in addressing the problem. For the technicians, it is as if the notification responsibility is for the nurses; for NSP members, it is as if responsibility is not shared by all. AE notification is not the responsibility of a single professional category; however, one study revealed that responsibility for safety is not shared equally by all teams ${ }^{(26)}$.

Another aspect concerns the absence of analyzing the causes. Following the notification there are a series of interlinked actions: analyzing the event and the risk situation, directing learning aimed at improving the safety of patients during their hospitalization ${ }^{(25)}$. It is a systematic process that analyzes the factors that contribute to an incident, identified by reconstructing the sequence of events and by the constant questioning of its occurrence until its elucidation; a tool that needs to be better used to ensure patient safety, assisting in the actions to be taken to reduce and manage future damage ${ }^{(27)}$.

Therefore, just notifying is not enough; in addition, managers must outline a process to analyze the data, to give feedback to the team and to proactively insert changes. Communication problems, interactions between leaders, NSP and other professionals need to be solved. Despite this scenario, the participants of the research recognize the importance of the notification and their testimonies are in agreement with what is discussed in the literature. This assigned value may be the initial step toward reality change.

Notification reduces or eliminates similar occurrences in the future, promotes learning, and useful information is generated to correct failures through investigation and analysis of incidents. A system based on a continuous reporting/ no-fault notification attitude is essential, focusing on the learning process, redesign and generating applicable knowledge, of proactivity in relation to adverse events ${ }^{(12)}$.

Recognition of the importance of reporting reveals potential for improving outcomes and can be achieved by investing in the team through education, encouraging reporting, and a managerial posture that reinforces a nonpunitive culture. In this perspective, some authors propose a just culture, an approach that differentiates the moments in which an error or an unsafe act must be treated by a systemic approach and not of guilt, and situations in which a more focused response on personal responsibility is necessary ${ }^{(20)}$.

According to the presented results, it is observed that the routine procedures during notification practice do not prevail, but rather a combination of ways to communicate the $\mathrm{AE}$ which require attention from the managers. The functional effectiveness of patient safety guidelines directly depends on the strictness of the interactions between all professionals working in the hospital setting, especially the leaders, NSP members, and the nursing staff. The main limitations of the research are due to the adopted methodology, since case studies do not allow generalizations, so the reality here does not necessarily represent the reality of other institutions.

\section{CONCLUSION}

The practice of AE notification was marked by fear and gaps in knowledge. There is a lack of relationship between leaders, members of the NSP and other professionals so that everyone can effectively assume their social roles in the field of patient safety at the hospital. It is necessary to overcome the various ways of communicating the $\mathrm{AE}$ in order to overcome the punitive reality, to establish anonymity in the notifications, presuming there is underreporting. This implies changes in habits, values and behaviors in relation to health care in the perspective of patient safety, thus influencing professional practice.

It is emphasized that this study allowed understanding reality as it is, and not as it should be, enabling to capture the way professionals act. In professional practice it is necessary 
to not only include the guidelines and norms, but also a continuous educational practice and to improve the communication between the leadership and those who are led, generating a more favorable environment for notification.
Involvement of the patient in reporting incidents can also help in developing safety culture. A positive aspect was to identify the importance that professionals give to the notification, a step to improve the results.

\section{RESUMO}

Objetivo: Compreender a prática de notificação de eventos adversos por profissionais de saúde. Método: Estudo de caso qualitativo, realizado em um hospital de ensino com participantes do Núcleo de Segurança do Paciente e a equipe de Enfermagem. A coleta ocorreu de maio a dezembro de 2015 e foi realizada por meio de entrevistas, observação e pesquisa documental para tratamento dos dados sob a Análise de Conteúdo. Resultados: Participaram da pesquisa 31 profissionais. Foram elaboradas três categorias: A prática de notificação de eventos adversos; Barreiras na prática efetiva de notificações; A importância da notificação de eventos adversos. Conclusão: A notificação estava permeada por lacunas no conhecimento, medo de punição e comunicação informal, gerando subnotificações. É preciso melhorar a interação entre líderes e profissionais, com ênfase na comunicação e prática educativa.

\section{DESCRITORES}

Segurança do Paciente; Equipe de Enfermagem; Gestão da Segurança; Qualidade da Assistência à Saúde; Erros Médicos.

\section{RESUMEN}

Objetivo: Comprender la práctica de notificación de eventos adversos por profesionales sanitarios. Método: Estudio de caso cualitativo, realizado en un hospital de enseñanza con participantes en el Núcleo de Seguridad del Paciente y el equipo de Enfermería. La recolección ocurrió de mayo a diciembre de 2015 y fue realizada mediante entrevistas, observación e investigación documental para tratamiento de los datos bajo Análisis de Contenido. Resultados: Participaron en la investigación 31 profesionales. Fueron elaboradas tres categorías: La práctica de notificación de eventos adversos; Barreras en la práctica efectiva de notificaciones; La importancia de la notificación de eventos adversos. Conclusión: En la notificación se interponían brechas de conocimiento, miedo de punición y comunicación informal, generando subnotificaciones. Es necesario mejorar la interacción entre líderes y profesionales, con énfasis en la comunicación y práctica educativa.

\section{DESCRIPTORES}

Seguridad del Paciente; Grupo de Enferméria; Gestión de la Seguridad; Calidad de la Atención de Salud; Errores Médicos.

\section{REFERENCES}

1. World Health Organization. Patient Safety. The conceptual framework for the International Classification for Patient Safety. Final Technical Report. Geneva: WHO; 2009.

2. Sousa P, Uva AS, Serranheira F, Nunes C, Leite ES. Estimating the incidence of adverse events in Portuguese hospitals: a contribution to improving quality and patient safety. BMC Health Serv Res [Internet]. 2014 [cited 2016 May 18];14:311. Available from: http://www. biomedcentral.com/1472-6963/14/311

3. Sousa P. Patient safety: a necessidade de uma estratégia nacional. Acta Med Port 2006;19:309-18.

4. Mendes W, Martins M, Rozenfeld S, Travassos C. The assessment of adverse events in hospitals in Brazil. Int J Qual Health Care [Internet]. 2009 [cited 2016 May 18]; 21(4):279-84. Available from: https:/academic.oup.com/intqhc/article-lookup/doi/10.1093/intqhc/mzp022

5. Aranaz-Andrés JM, Aibar-Remón C, Vitaller-Murillo J, Ruiz-López P, Limón-Ramírez R, Terol-García E. Incidence of adverse events related to health care in Spain: results of the Spanish National Study of Adverse Events. J Epidemiol Community Health. 2008;62(12):1022-9.

6. Brasil. Ministério da Saúde. Portaria n. 529, de $1^{\circ}$ de abril de 2013. Institui o Programa Nacional de Segurança do Paciente [Internet]. Brasília; 2013 [citado 2016 jun.12]. Disponível em: http://bvsms.saude.gov.br/bvs/saudelegis/gm/2013/prt0529_01_04_2013.html

7. Bezerra ALQ, Silva AEBC, Branquinho NCSS, Paranaguá TTB. Análise de queixas técnicas e eventos adversos notificados em um hospital sentinela. Rev Enferm UERJ. 2009;17(4):467-72.

8. Bunkenborg G, Samuelson K, Akeson J, Poulsen I. Impact of professionalism in nursing on in-hospital bedside monitoring practice. J Adv Nurs. 2012;69(7):1466-77.

9. Carvalho RE, Cassiani SH. Cross-cultural adaptation of the Safety Attitudes Questionnaire - Short Form 2006 for Brazil. Rev Latino Am Enfermagem. 2012;20(3):575-82.

10. Lorenzini E, Santi JAR, Báo ACP. Patient safety: analysis of the incidents notified in a hospital, in south of Brazil. Rev Gaúcha Enferm. 2014;35(2):121-7.

11. Yin RK. Estudo de caso: planejamento e métodos. 5a ed. Porto Alegre: Bookman; 2015.

12. Bardin L. Análise de conteúdo. Lisboa: Edições 70; 2011.

13. Organización Panamericana de la Salud (OPAS). Sistemas de notificación de incidentes en América Latina. Washington: OPS; 2013.

14. Capucho HC, Arnas ER, Cassiani SHB. Patient safety: a comparison between handwritten and computerized voluntary incidente reporting. Rev Gaúcha Enferm. 2013;34(1):164-72.

15. Antonoff MB, Berdan EA, Kirchner VA, Krosch TC, Holley CT, Maddaus MA, et al. Who's covering our loved ones: surprising barriers in the sign-out process? Am J Surg. 2013;205(1):77-84. 
16. Massoco ECP, Melleiro MM. Comunicação e segurança do paciente: percepção dos profissionais de enfermagem de um hospital de ensino. Rev Min Enferm. 2015; 19(2):187-91.

17. Leitão IMTA, Oliveira RM, Leite SS, Sobral MC, Figueiredo SV, Cadete MC. Análise da comunicação de eventos adversos na perspectiva de enfermeiros assistenciais. Rev Rene. 2013;14(6):1073-83.

18. Duarte SCM, Stipp MAC, Silva MM, Oliveira FT. Eventos adversos e segurança na assistência de enfermagem. Rev Bras Enferm. 2015;68(1):144-54.

19. Corbellini VL, Schilling MCL, Frantz SF, Godinho TG, Urbanetto JS. Eventos adversos relacionados a medicamentos: percepção de técnicos e auxiliares de enfermagem. Rev Bras Enferm. 2011;64(2):241-7.

20. Wachter RM. Personal accountability in healthcare: searching for the right balance. BMJ Qual Saf. 2013;22(2):176-80.

21. Griffiths P, Maben J, Murrells T. Organisational quality, nurse staffing and the quality of chronic disease management in primary care: observational study using routinely collected data. Int J Nurs Stud. 2011;48(10):1199-210.

22. Paese F, Sasso GTMD. Patient safety culture in primary health care. Texto Contexto Enferm. 2013;22(2):302-10.

23. Bjertnaes O, Deilkas ET, Skudal KE, Iversen HH, Bjerkan AM. The association between patient-reported incidents in hospitals and estimated rates of patient harm. Int J Qual Health Care. 2015;27(1):26-30.

24. Mendes W, Pavão ALB, Martins M, Moura MLO, Travassos C. The feature of preventable adverse events in hospitals in the State of Rio de Janeiro. Rev Assoc Med Bras [Internet]. 2013 [cited 2016 May 18];59(5):421-8. Available from: http://www.scielo.br/pdf/ramb/v59n5/ en_v59n5a06.pdf

25. Paiva MCMS, Popim RC, Melleiro MM, Tronchim DMR, Lima SAM, Juliani CMCM. The reasons of the nursing staff to notify adverse events. Rev Latino Am Enfermagem. 2014;22(5):747-54.

26. Bohomol E, Tartali JA. Adverse effects in surgical patients: knowledge of the nursing professionals. Acta Paul Enferm. 2013;26(4):376-81.

27. Toffoletto MC, Ruiz XR. Improving patient safety: how and why incidences occur in nursing care. Rev Esc Enferm USP. 2013;47(5):1098105. DOI: http://dx.doi.org/10.1590/S0080-623420130000500013

\section{Financial Support:}

Fundação de Amparo à Pesquisa do Estado de Minas Gerais - FAPEMIG

Process PPM-00404-15 - Programa Pesquisador Mineiro - PPM IX

\section{ERRATUM}

The following information is inserted in page 8:

"Financial support:

Fundação de Amparo à Pesquisa do Estado de Minas Gerais - FAPEMIG Process PPM-00404-15 - Programa

Pesquisador Mineiro - PPM IX"

\section{Rev Esc Enferm USP • 2018;52:e03322}

